\title{
Temporal specificity in patterning of the rabbit nictitating membrane response
}

\author{
GABRIELLE WEIDEMANN, ANASTASIA GEORGILAS, and E. JAMES KEHOE \\ University of New South Wales, Sydney, Australia
}

\begin{abstract}
Rabbits were trained in either positive patterning $\left(\mathrm{AX}_{+}, \mathrm{A}-, \mathrm{X}-\right)$ or negative patterning $\left(\mathrm{A}_{+}, \mathrm{X}_{+}\right.$, $\mathrm{AX}-$ ) using one of four intervals between the onset of $\mathrm{A}$ and the onset of $\mathrm{X}$ on $\mathrm{AX}$ trials. These intervals were $0,800,2,400$, and $5,600 \mathrm{msec}$. In each task, all groups acquired an appropriate pattern of discriminative responding. Following acquisition, all rabbits were tested with the four different A-X intervals. All positive patterning groups showed an excitatory gradient, in which the highest level of responding occurred at the interval used in training. Conversely, all but one of the negative patterning groups showed an inhibitory gradient, in which the lowest level of responding occurred at the interval used in training. The one exception was the negative patterning group trained with simultaneous $\mathrm{AX}$ stimuli $(0 \mathrm{msec})$, which showed a low, broad gradient, indicating transfer of inhibition across all the intervals. The results are discussed with respect to temporal encoding mechanisms and accounts of conditional discriminations.
\end{abstract}

The present experiments were aimed at delineating the time course of integration in compounds of two stimuli. These experiments are most closely related to recent research examining transfer along temporal dimensions of compound stimuli. Most notably, Holland, Hamlin, and Parsons (1997) trained an appetitive response in rats in a serial feature positive discrimination $(\mathrm{A} \rightarrow \mathrm{X}+, \mathrm{X}-)$. The animals were then tested with a range of feature-target $(\mathrm{A} \rightarrow \mathrm{X})$ intervals. Test performance was better when the target stimulus (X) was presented at its customary time after the feature cue (A) than when the target was presented at an earlier or later time. For example, one group of animals was trained with a 5-sec feature-target interval, and the test intervals ranged from 0 to $65 \mathrm{sec}$. The animals showed the greatest discrimination with a 5-sec test interval. When tested with either simultaneous stimuli $(0 \mathrm{sec})$ or the next longest serial interval $(10 \mathrm{sec})$, discriminative responding dropped away equally. In summary, altering the feature-target interval yielded a gradient centered on the interval used in training.

Further evidence of temporal control has also appeared in a simultaneous feature negative task $(\mathrm{A}+, \mathrm{AX}-)$ (Barnet \& Miller, 1996; Denniston, Cole, \& Miller, 1998). For example, in Denniston et al.'s (1998) first experiment, rats were given pairings of two $\mathrm{CSs}(\mathrm{A}+, \mathrm{B}+)$ with a shock US, each at a CS-US interval of 5 and $10 \mathrm{sec}$, respectively. Each of these CSs was also given nonreinforced presentations in compound with another stimulus $(\mathrm{AX}-, \mathrm{BY}-)$, with the aim of establishing the $\mathrm{X}$ and $\mathrm{Y}$ stimuli as conditioned inhibitors of fear. Another two CSs (D, C) were also given reinforced pairings at the same CS-US intervals as

Preparation of this manuscript was supported by Australian Research Council Grant A79600502. Correspondence should be sent to E. James Kehoe, School of Psychology, University of New South Wales, Sydney, NSW 2052, Australia (e-mail: j.kehoe@unsw.edu.au).
A and B, respectively. After this training, D and C substantially disrupted appetitive drinking. Tests were then conducted with compounds of DX, DY, CX, and CY. They indicated that the ability of the $\mathrm{X}$ and $\mathrm{Y}$ stimuli to inhibit fear was specific to the time at which the expected US was omitted on the AX - and BY - training trials. That is, DX and $C Y$ produced the least disruption of drinking, while DY and CX produced intermediate levels of disruption.

Although rats show specificity in transfer along temporal dimensions, previous findings indicate that other species and their response systems may show less specificity and, accordingly, greater transfer. In particular, Rescorla (1989) examined temporal transfer of autoshaped keypecking in pigeons. In his Experiment 1, each bird was given feature negative training containing a reinforced stimulus $(\mathrm{X}+)$, a nonreinforced compound of simultaneous stimuli $(\mathrm{AX}-)$, and a nonreinforced compound of serial stimuli $(\mathrm{B} \rightarrow \mathrm{X}-$ ). In addition, each bird received a separate nonreinforced stimulus $(\mathrm{C}-)$ and a reinforced stimulus $(\mathrm{Y}+)$. Tests were then conducted in which the three nonreinforced stimuli were compounded with the excitatory $\mathrm{Y}$ stimulus, both simultaneously (AY) and serially $(A \rightarrow Y)$. Both of the potential conditioned inhibitors (A, B) reduced responding to $Y$ to about the same degree regardless of whether they were tested simultaneously or serially. Nevertheless, there was evidence that the pigeons were sensitive to the temporal arrangement of the stimuli, because the simultaneous tests yielded greater suppression than did the serial tests. The third nonreinforced stimulus (C) did not appear to suppress responding to $Y{ }^{1}$

Despite the differing degrees of specificity, the evidence for transfer along temporal dimensions of compound stimuli has intriguing implications for purported differences in the mechanisms engaged by simultaneous versus serial compounds. Studies using simultaneous stimuli have pointed to configural mechanisms in which the per- 
ceptual encoding of the compound has its own associative strength distinct from encodings of the individual stimuli (Bellingham, Gillette-Bellingham, \& Kehoe, 1985; Kehoe \& Gormezano, 1980; Pearce, 1987, 1994). Studies using serial stimuli, on the other hand, have pointed to hierarchical mechanisms which assume that the two stimuli take on different roles (Bonardi, 1996). The first stimulus is thought to act on the association of the second stimulus with the reinforcer by either (1) exercising superordinate control over memory retrieval described as "occasion setting" or "facilitation" (Holland, 1983, 1992; Rescorla, 1985 ) or (2) evoking an appropriate motivational state for responding (Brandon \& Wagner, 1991; Konorski, 1967). However, from theoretical, operational, and empirical perspectives, it has become less and less certain whether there is a tidy division between the two types of compounds.

From a theoretical perspective, attempts have been made to extend the alternative hypotheses to all types of compound. There are configural hypotheses for serial stimuli (e.g., Holland \& Reeve, 1991; Kehoe, MarshallGoodell, \& Gormezano, 1987) and hierarchical hypotheses for simultaneous stimuli (Holland, 1989b; Holland \& Haas, 1993). Furthermore, the alternative hypotheses are not mutually exclusive, and, recently, connectionist models have attempted to reduce configural and hierarchical mechanisms to special cases of a single theoretical process (Schmajuk \& Buhusi, 1997; Schmajuk, Lamoureux, \& Holland, 1998; Wagner, 1992). Consequently, any theoretical differences between simultaneous and serial compounds may be quantitative rather than qualitative.

From an operational perspective, the tasks favoring different mechanisms have differed not only in their temporal arrangements--simultaneous versus serial-but also in stimulus-reinforcer contingencies. One of the tasks used commonly to demonstrate configural learning has been negative patterning $(\mathrm{A}+, \mathrm{X}+, \mathrm{AX}-)$, in which presentations of two individual stimuli are reinforced while their compound $\mathrm{AX}$ is never reinforced (Pavlov, 1927, p. 144). To explain the ability of animals to respond on $\mathrm{A}+$ and $\mathrm{X}+$ trials while withholding the response on $\mathrm{AX}-$ trials, has seemed to require a distinctive encoding of the compound (Kehoe \& Gormezano, 1980; Woodbury, 1942). According to configural hypotheses, the encodings of the individual $A$ and $X$ stimuli would each carry excitatory associative strength, while the encoding of the AX compound would carry either no associative strength or an inhibitory strength.

In contrast to negative patterning, the stimulusreinforcer contingencies commonly used to demonstrate hierarchical processes have been conditional discriminations, particularly the serial feature positive schedule $(\mathrm{A} \rightarrow \mathrm{X}+, \mathrm{X}-)$, the serial feature negative schedule $(\mathrm{X}+$, $\mathrm{A} \rightarrow \mathrm{X}-)$, and a hybrid of the two $(\mathrm{A} \rightarrow \mathrm{X}+, \mathrm{B} \rightarrow \mathrm{X}-)$. The initial feature cues $(A, B)$ predict accurately whether or not the US will occur. The later target stimulus $(X)$ is a less valid predictor of the US. However, by virtue of its close contiguity with the US, the target stimulus is a more accurate signal that the US is imminent. In summary, the feature cue signals the reinforcer's likelihood and the target stimulus signals the time of reinforcer delivery (Holland, 1992).

Although patterning and conditional discriminations have been studied in different theoretical contexts, the two types of discrimination do not appear to diverge at the divide between simultaneous and serial stimuli. In fact, both types of discrimination have been obtained using both types of compound. Holland and Reeve (1991) demonstrated patterning of both types using both simultaneous and serial compounds in rats in an appetitive instrumental task. Conversely, using classical conditioning of the rabbit's nictitating membrane (NM) response, Weidemann and Kehoe (1997) demonstrated the acquisition of a conditional discrimination in a hybrid task $(\mathrm{AX}+, \mathrm{BX}-)$ using both simultaneous and serial arrangements. This initial acquisition was followed by extinction of the positive feature cue $(\mathrm{A}-)$ and reinforcement of the negative feature cue $\left(\mathrm{B}^{+}\right)$. In subsequent tests with the target stimulus, this reversed training of the feature cues interfered with the original discrimination to an equal degree in both simultaneous and serial compounds.

Not all evidence, however, has favored a continuity between simultaneous and serial stimuli. Some posttraining manipulations of the feature cue have had different effects on simultaneous and serial conditional discriminations. For example, Holland (1989a) found that, after a simultaneous discrimination $(\mathrm{AX}+, \mathrm{X}-)$ had been established in rats by using appetitive conditioning, extinction presentations of the feature cue $(\mathrm{A}-)$ substantially reduced responding to the $\mathrm{AX}$ compound. However, after a serial discrimination $(A \rightarrow X+, X-)$, extinction of the feature cue $\left(\mathrm{A}^{-}\right)$produced little disruption in responding to the $A \rightarrow X$ compound. Rescorla (1986) has found similar results in pigeon autoshaping.

Even if not all evidence implies a continuity between simultaneous and serial stimuli, the available theoretical, operational, and empirical considerations suggest that there is a greater continuity than previously suspected. That is, simultaneity of stimuli may be merely an endpoint along the dimension of temporal relationships within compound stimuli. However, there are key empirical questions that need answering before a theoretical distinction between simultaneous and serial stimuli is abandoned:

1. Does the apparent continuity depend on one stimulus's being a superior predictor of the US relative to the other stimulus? Examinations of temporal transfer have used only feature positive and feature negative conditional discriminations. There are no similar temporal transfer studies using patterning schedules.

2 . Is there a symmetry in transfer between simultaneous and serial stimuli? Rescorla's (1989) findings indicate complete symmetry in temporal transfer, but the other available findings are less instructive. Holland et al. (1997) tested animals with both types of compound but conducted initial training using only serial stimuli. Miller and his collaborators manipulated CS-US intervals but always used simultaneous compounds. 
3. Does continuity appear across small time scales? The previous studies used stimuli that were often 5 or more seconds in duration and serial intervals that were also 5 or more seconds in length. It remains to be determined how broad or narrow the temporal gradients will be when the stimuli and their serial intervals are much shorter.

4 . What is the degree of temporal specificity encountered across species and their response systems? Rescorla (1989) found broad transfer in pigeons' keypecking, but the results from rat paradigms have yielded pronounced gradients.

The present experiments addressed these questions in the following fashion. First, patterning schedules were used to eliminate the superior predictive power of the feature cues in conditional discriminations. Positive patterning was used in Experiment 1 and negative patterning was used in Experiment 2. Second, initial training included simultaneous stimuli as well as serial stimuli. Third, the stimuli were very brief, $800 \mathrm{msec}$, and the intervals were manipulated over values less than $5 \mathrm{sec}$. Fourth, the experiments tested the scope of temporal transfer using a species and response system different from those used in previous studies-namely, the rabbit's nictitating membrane response.

\section{EXPERIMENT 1}

Rabbits were trained initially in a positive patterning schedule $(\mathrm{AX}+, \mathrm{A}-, \mathrm{X}-)$ using one of four intervals on $\mathrm{AX}+$ trials. They included the simultaneous presentation of $A$ and $X(0 \mathrm{msec})$ as well as three serial intervals between the onset of the A stimulus and the subsequent onset of the $X$ stimulus $(800,2,400$, and $5,600 \mathrm{msec})$. Following acquisition of the discrimination, all rabbits were tested with the four different intervals.

\section{Method}

Subjects. Experiment 1 used 32 albino rabbits (Oryctolagus cuniculus), 16 female and 16 male. On arrival from the university's breeding unit, they were 70-80 days old and weighed approximately $1.5 \mathrm{~kg}$. All rabbits were individually housed and had free access to food and water.

Apparatus. The apparatus and recording procedures for the NM response were modeled on those described by Gormezano (1966). Each subject was restrained in a Perspex box and trained individually in one of eight ventilated chambers. In each chamber, a speaker was mounted approximately $8 \mathrm{~cm}$ anterior to and $16 \mathrm{~cm}$ above the subject's head. The speaker provided the two auditory stimuli, namely, a 1000-Hz, 89-dB (SPL) tone and an 89-dB (SPL) burst of white noise. Both auditory stimuli were superimposed on a constant background noise ( $81-\mathrm{dB}, \mathrm{SPL})$ provided by a ventilating fan positioned at the rear of the conditioning chamber. An 8 -W neon light tube, mounted $4 \mathrm{~cm}$ above the speaker, served as the houselight. The light also served as the source of two visual stimuli, namely, houselight off and houselight pulsed at the rate of $20 \mathrm{~Hz}$. Both the auditory and visual stimuli were $800 \mathrm{msec}$ in duration. The US was a 50 msec, 3-mA, 50-Hz ac current delivered via stainless steel Autoclip wound clips positioned $10 \mathrm{~mm}$ apart, $15 \mathrm{~mm}$ posterior to the lateral canthus of the rabbit's right eye. The stimulus events and response recording were controlled by an Apple II computer equipped with interfaces and software developed by Scandrett and Gormezano (1980).

To transduce NM movements, a small hook was attached to a silk loop sutured into the NM of the rabbit's right eye. The hook was connected to one end of an L-shaped crank that operated a photoelectric transducer (Gormezano \& Gibbs, 1988). The signal from the phototransistor was amplified and transmitted to an analog-todigital converter (10-msec sample rate) installed in the computer.

Procedure. All rabbits received 1 day of preparation, 2 days of recovery, and 1 day of adaptation before training began. On the day of preparation, hair posterior to the rabbit's right eye was removed and a small loop of surgical silk (000 Dynex) was sutured into the NM of the rabbit's right eye using a local anaesthetic (Opthaine). The rabbits were returned to their home cages for 2 days of recovery. On the day of adaptation, the animals were placed in the conditioning apparatus for $60 \mathrm{~min}$, but neither a CS nor a US was presented.

Following adaptation, the animals were randomly assigned to one of four groups $(n=8)$ designated as P0, P800, P2400, and P5600. The group labels correspond to the temporal arrangement of the auditory and visual stimuli during reinforced compound trials $(\mathrm{AX}+)$. For Group P0, the auditory and visual stimuli were presented simultaneously. For the remaining groups, the stimuli were presented serially, and their labels refer to the interval, in milliseconds, between the onset of the auditory stimulus (A) and the onset of the visual stimulus (X)-namely, $800,2,400$, and 5,600 $\mathrm{msec}$, respectively. On AX+ trials, the onset of the US coincided with the offset of the 800 -msec $\mathrm{X}$ stimulus.

On Days 1-6 of training, all animals received training with a positive patterning schedule. Each day consisted of 32 reinforced compound trials $(\mathrm{AX}+), 16$ nonreinforced presentations of the auditory stimulus $(\mathrm{A}-)$, and 16 nonreinforced presentations of the visual stimulus $(\mathrm{X}-)$. For half of the animals in each group, A was a $1000-$ $\mathrm{Hz}$ tone and $\mathrm{X}$ was a flashing houselight; for the other half of the animals, $A$ was white noise and $\mathrm{X}$ was a period of darkness. These trials were presented randomly, and no more than three trials of any one type occurred consecutively. The mean intertrial interval (ITI) was $60 \mathrm{sec}$.

On Days 7-12, the training schedule continued, but all groups were presented with an additional eight nonreinforced compound test trials $(\mathrm{AX}-)$. These consisted of two trials of each $\mathrm{A}-\mathrm{X}$ interval, namely, $0,800,2,400$, and $5,600 \mathrm{msec}$. A test trial was presented following every eight training trials.

Response definition. A conditioned response (CR) was defined as any extension of the $\mathrm{NM}$ exceeding $0.5 \mathrm{~mm}$ initiated following the onset of a CS. For A - and X-trials, responses in the $800-\mathrm{msec}$ duration of the $\mathrm{CS}$ were recorded as $\mathrm{CRs}$. For $\mathrm{AX}+$ training trials and $\mathrm{AX}$ - test compounds, only responses during the 800 -msec $\mathrm{X}$ portion of $\mathrm{AX}$ - test compounds were counted in order to ( 1 ) equate the observation interval over trial types and (2) reflect the conditional control of responding to $\mathrm{X}$ by $\mathrm{A}$. In all statistical analyses, the rejection level was set according to a Type I error rate of .05 .

\section{Results and Discussion}

Acquisition of positive patterning. Figure 1 depicts the $\mathrm{CR}$ likelihood to the compound $(\mathrm{AX}+)$ and the components $(\mathrm{A}-, \mathrm{X}-)$. The means shown in the figure represent the proportion of each type of trial containing a $\mathrm{CR}$ on Day 12. As can be seen, positive patterning occurred. Across the four groups, the main effect comparison confirmed that the mean level of responding during the $\mathrm{AX}+$ trials was significantly higher than the maximum of either $\mathrm{A}-$ or $\mathrm{X}$ - trials $[F(1,28)=91.46, p<.01]$. Any apparent differences in the degree of discrimination across groups were small and failed to reach significance. That 


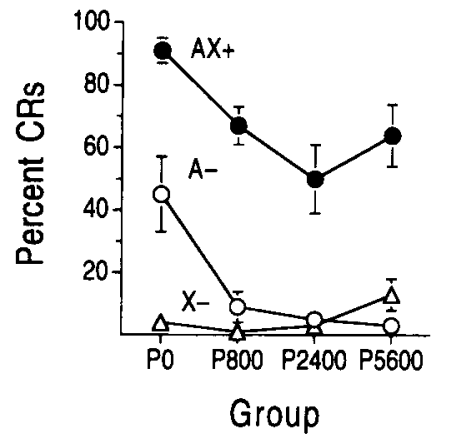

Figure 1. Mean percent CRs $( \pm 1 S E)$ on $\mathrm{AX}+, \mathrm{A}-$, and $\mathrm{X}-$ training trials as a function of the groups variable in Experiment 1 . The $P$ in the group label indicates the positive patterning schedule, and the number indicates the $A-X$ interval on $A X+$ training trials.

is, the interactions between the main effect comparison and trend comparisons across groups did not reach significance [largest $F(1,28)=1.71, p>.20$ ].

Among groups, only Group P0's performance stands out. In the other groups, responding to the components was less than $15 \%$. In Group P0, however, responding on A - trials was more substantial, averaging around $40 \%$. Statistical comparisons confirmed that responding to A - declined across groups [linear $F(1,28)=18.61, p<$ $.05]$. On AX+ trials, Group P0's level of $91 \%$ appeared higher than that in the other groups, which averaged around $67 \%$. However, this difference failed to reach statistical significance $[F(1,28)=3.70, p>.05]$.

Interval tests. Figure 2 depicts the $C R$ likelihood on compound test trials as a function of the $\mathrm{A}-\mathrm{X}$ interval. For each group, the maximum level of responding appeared for the $\mathrm{A}-\mathrm{X}$ interval used on compound training trials. As the test interval deviated from the training interval, the level of responding during the compound declined progressively. The degree of temporal specificity was particularly pronounced in the groups trained with the shorter $\mathrm{A}-\mathrm{X}$ intervals. The simultaneous group, Group $\mathrm{P} 0$, showed a steep gradient as the $\mathrm{A}-\mathrm{X}$ interval was increased from 0 to $800 \mathrm{msec}$. In Group P800, the gradient was equally steep and, moreover, was symmetric around its training interval of $800 \mathrm{msec}$. That is, there were large decrements in responding when the interval was either shortened to the 0 -msec value or increased to the 2,400-msec value. In contrast, Groups P2400 and P5600 showed gradients with shallower slopes.

Statistical analyses confirmed the shapes of the gradients shown in Figure 2. For Group P0, there was a significant linear decline and also a quadratic component in performance as a function of the A-X test interval $[F \mathrm{~s}(1,28)=109.17$ and $27.60, p \mathrm{~s}<.05]$. Similarly, for Group P800, there were both significant linear and quadratic trends in responding across test intervals $[F \mathrm{~s}(1,28)=$ 13.16 and $21.44, p s<.05]$. In the case of Group P2400, there was a significant quadratic trend in the performance across test intervals $[F(1,28)=15.83, p<.05]$. Finally, for Group P5600, there were significant linear increases in responding as a function of the test interval $[F(1,28)=$ $20.53, p<.05]$.

In summary, the major findings of the present experiment were as follows: (1) All groups attained discriminative responding in a positive patterning schedule to a similar degree. (2) The simultaneous presentation of the components in Group P0 produced a higher overall level of responding, particularly on A+ trials, relative to the serial groups. (3) Altering the A-X interval on test trials yielded a temporal gradient that was centered on the interval used in training.

\section{EXPERIMENT 2}

In Experiment 2, negative patterning as a function of the $\mathrm{A}-\mathrm{X}$ interval in training and testing was investigated. Rabbits were initially given reinforced training with the individual components $(\mathrm{A}+, \mathrm{X}+)$ before nonreinforced presentations of the compound $(\mathrm{AX}-)$ were introduced into the schedule. Previous research has revealed that a ratio of four compound trials to each component trial is needed for the appearance of negative patterning in the rabbit NM preparation (Kehoe \& Graham, 1988). To start training with such a high ratio of nonreinforced-toreinforced trials, however, has proved inimical to any CR acquisition, but preliminary training with the components has enabled the animals to solve the negative patterning problem (Bellingham et al., 1985; Experiment 2).

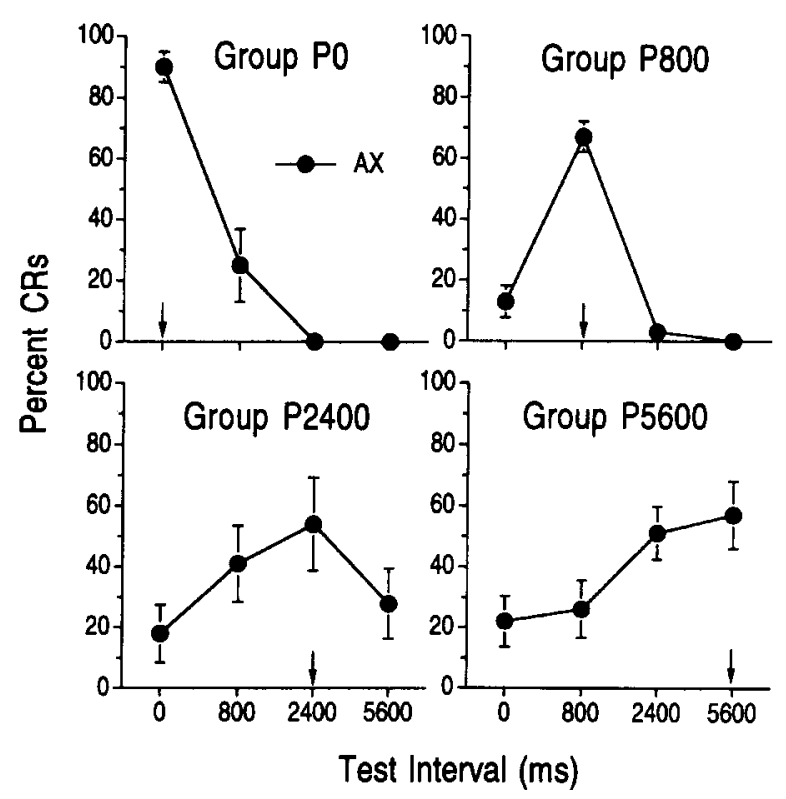

Figure 2. Mean percent CRs $( \pm 1 S E$ ) on $A X$ test trials as a function of the $A-X$ interval in Experiment 1. Each panel shows the results for a different group. The $P$ in the group label indicates the positive patterning schedule, and the number indicates the $\mathrm{A}-\mathrm{X}$ interval on $\mathrm{AX}+$ training trials. 


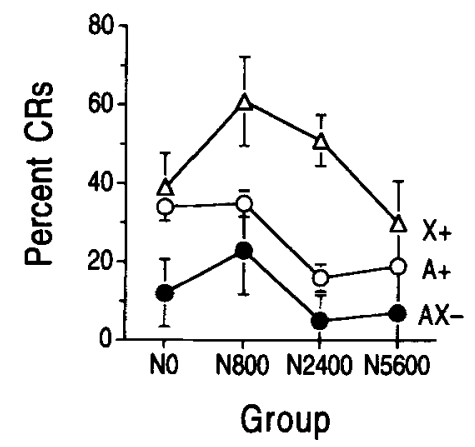

Figure 3. Mean percent $\mathrm{CRs}( \pm 1 S E)$ on $\mathrm{A}+, \mathrm{X}+$, and $\mathrm{AX}-$ training trials as a function of the groups variable in Experiment 2 . The $\mathbf{N}$ in the group label indicates the negative patterning schedule, and the number indicates the $A-X$ interval on $A X-$ training trials.

\section{Method}

Subjects. Experiment 2 used 32 male albino rabbits (Oryctolagus cuniculus).

Apparatus and Procedure. Unless otherwise noted, the apparatus and recording procedures were identical to those used in Experiment 1 . All rabbits received 1 day of preparation, 2 days of recovery, and 1 day of adaptation before training began. The animals were trained in two successive replications. Prior to Stage 1 , the animals in the first replication received 8 days of training with two CSs in a stimulus compounding experiment, in which the CS-US interval was $300 \mathrm{msec}$ for one CS and $600 \mathrm{msec}$ for the other CS. In contrast, the animals in the second replication were naive prior to the start of Stage 1.

In Stage 1, all animals received $30 \mathrm{~A}+$ trials and $30 \mathrm{X}+$ trials, both with an 800 -msec CS-US interval (onset to onset). The A stimulus was a $1000-\mathrm{Hz}$ tone, and the $\mathrm{X}$ stimulus was a $20-\mathrm{Hz}$ flashing houselight. The first replication received 4 days of training, and the second replication received 8 days. Animals in both replications reached an average of $75 \% \mathrm{CRs}$ on both $\mathrm{A}+$ and $\mathrm{X}+$ trials. The mean ITI was $60 \mathrm{sec}$.

In Stage 2, all animals received training in a negative patterning schedule $(\mathrm{A}+, \mathrm{X}+, \mathrm{AX}-)$, in which the rabbits were randomly assigned to one of four groups $(n=8)$ designated as Groups N0, $\mathrm{N} 800, \mathrm{~N} 2400$, and $\mathrm{N} 5600$. For Group N0, the stimuli in the AXtrials were presented simultaneously. For the remaining groups, the stimuli were presented serially; the intervals between the onset of $A$ and the onset of $X$ were $800,2,400$, and $5,600 \mathrm{msec}$ for Groups $\mathrm{N} 800, \mathrm{~N} 2400$, and $\mathrm{N} 5600$, respectively. In the first replication, each group received 3 days of training, each containing $10 \mathrm{~A}+$ trials, 10 $\mathrm{X}+$ trials, and $40 \mathrm{AX}-$ trials. This ratio of 1 reinforced trial for each individual CS to 4 nonreinforced compound trials nearly extinguished responding on all trials. Accordingly, training was switched to a $1: 2$ ratio, specifically, $15 \mathrm{~A}+$ trials, $15 \mathrm{X}+$ trials, and $30 \mathrm{AX}-$ trials per day. After 10 days of training with the $1: 2$ ratio, the animals were returned to the 1:4 ratio for 5 days prior to Stage 3 . In the second replication, each group received 10 days of the $1: 2$ ratio and then 7 days of the $1: 4$ ratio.

In Stage 3 , there were 6 days of training and testing. The animals in both replications continued to receive training with the $1: 4$ ratio used at the end of Stage 2. In addition, they received two test trials of the AX compound at each of the four A-X intervals- namely, 0 , $800,2,400$, and $5,600 \mathrm{msec}$. A test trial was presented randomly after every eighth training trial.

Response definition. As in Experiment 1, a CR was defined as any extension of the NM exceeding $0.5 \mathrm{~mm}$ initiated following the onset of a CS. For $\mathrm{A}+$ and $\mathrm{X}+$ trials, only responses initiated prior to the US were recorded as CRs. On AX - trials, only responses during X's portion of the compound were counted as CRs in order to (1) equate the observation interval across groups and $A-X$ intervals, and (2) measure conditional control of responding to $X$ by $A$. In all statistical analyses, the rejection level was set according to a Type I error rate of .05 .

\section{Results and Discussion}

Acquisition of negative patterning. Figure 3 shows the CR likelihood on $\mathrm{A}+, \mathrm{X}+$, and $\mathrm{AX}$ - trials on the last day of training. All four groups showed evidence of negative patterning. Across the four groups, the main effect comparison confirmed that the mean level of responding during the $\mathrm{AX}$ - compound was significantly lower than the minimum of either $\mathrm{A}+$ or $\mathrm{X}+$ trials $[F(1,28)=$ $14.47, p<.01]$. Although Group N0 appeared to show a greater discrimination than the serial groups, the interactions between the main effect comparison and the trend comparisons across groups did not even approach significance $(F \mathrm{~s}<1)$.

In addition to successful negative patterning, there were some other differences that can be seen in Figure 3. Specifically, responding was significantly lower on A+ trials than on $\mathrm{X}+$ trials $[F(1,28)=46.41, p<.01]$. Moreover, the mean level of responding on both $\mathrm{AX}-$ and $\mathrm{A}+$ trials showed downward linear trends across groups $[F \mathrm{~s}(1,28)=$ $7.73,5.72, p \mathrm{~s}<.05]$. Any apparent differences among groups in responding on $\mathrm{X}+$ trials were not significant.

Interval tests. Figure 4 depicts $C R$ likelihood during AX test trials as a function of the $\mathrm{A}-\mathrm{X}$ test interval in Stage 3. With the exception of Group N0, the pattern of responding on the interval tests displayed an inhibitory gradient. That is, for the serial groups, the lowest level of responding on AX test trials was associated with the interval used in training. As the test interval deviated from the training interval, the level of responding during the compound progressively increased.

Statistical analyses confirmed that there were inhibitory gradients in responding for each of the serial groups. Specifically, for Group N800, there was a trough in performance centered at the 800 -msec interval, which was confirmed by a significant quadratic trend $[F(1,28)=$ $11.32, p<.05]$. Group N2400 also showed a trough in performance but centered on the 2,400 -msec interval [quadratic trend $F(1,28)=13.63, p<.05$ ]. There was also a significant downward linear trend in Group N2400's performance as a result of the high level of responding elicited by the simultaneous $\mathrm{AX}$ compound relative to the other compounds $[F(1,28)=10.92, p<.05]$. Finally, Group N5600 showed its lowest level of responding at the 5,600-msec interval and progressively higher levels of responding at the shorter intervals. This gradient resulted in significant linear and quadratic trends in responding across intervals $[F \mathrm{~s}(1,28)=17.60,10.51, p<.05]$.

In contrast to the inhibitory gradients seen in the serial groups, Group N0's performance showed broad transfer across all test intervals. Responding on the simultaneous 


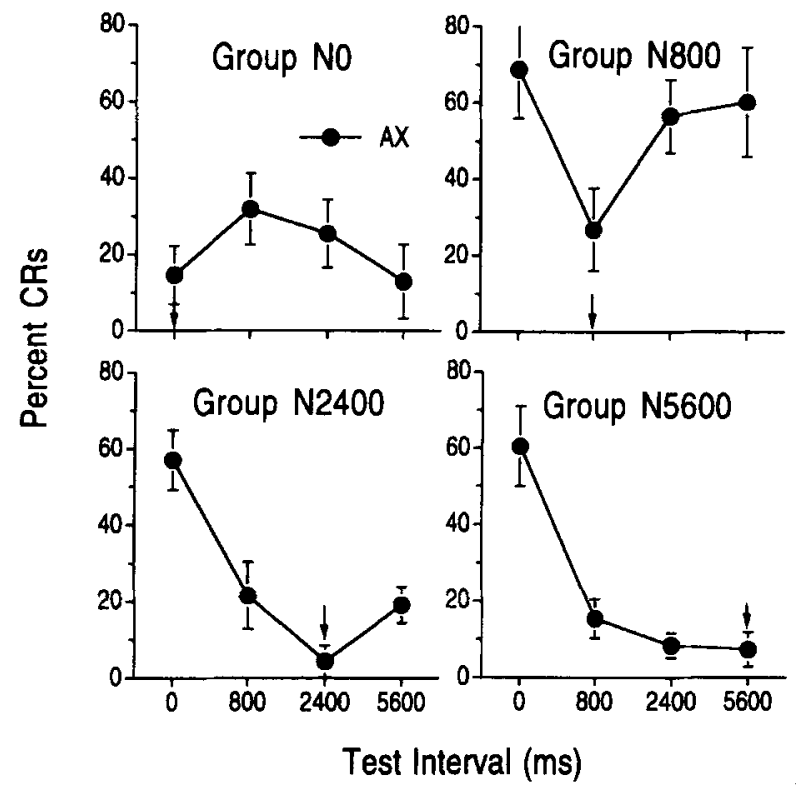

Figure 4. Mean percent CRs $( \pm 1 S E)$ on $\mathrm{AX}$ test trials as a function of the $A-X$ interval in Experiment 2 . The $N$ in the group label indicates the negative patterning schedule, and the number indicates the $\mathrm{A}-\mathrm{X}$ interval on $\mathrm{AX}$ - training trials.

AX test trial, which corresponded to Group N0's training interval, was appropriately low $(M=15 \%)$. Responding to $\mathrm{AX}$ increased to $32 \%$ when tested with the $800-\mathrm{msec}$ interval. However, when tested with the 2,400- and 5,600msec intervals, responding declined to levels of $25 \%$ and $13 \%$. This inverted $U$-shaped function was just barely significant $[F(1,28)=4.77, p<.05]$.

In summary, the major findings of Experiment 2 were: (1) All groups acquired negative patterning to about the same degree. (2) In the serial groups, altering the $A-X$ interval on test trials yielded inhibitory gradients, in which responding to $\mathrm{AX}$ increased as the interval deviated from the value used in training. (3) In Group N0, responding on $\mathrm{AX}$ trials remained relatively low across all test intervals.

\section{GENERAL DISCUSSION}

With respect to our four original questions, the first concerned whether continuity between simultaneous and serial stimuli depended on the feature cue's being a superior predictor of the US relative to the target stimulus. In the present experiments, discriminative responding and temporal gradients were obtained for both simultaneous and serial stimuli using patterning, in which the nominal "feature" cue (A) was no more predictive of the US than was the nominal "target" stimulus (X). In addition, the present results provided the first demonstration of patterning using serial stimuli in the rabbit NM preparation, thus confirming and extending previous demonstrations of patterning using serial stimuli in rats (e.g., Holland \& Reeve, 1991; Ross \& Holland, 1982).

The second question concerned whether there was symmetry in transfer between simultaneous and serial stimuli.
The interval tests in the two experiments did not yield entirely congruent results. On the one hand, the gradients based on positive patterning in Experiment 1 indicated symmetric transfer going from simultaneous to serial stimuli or vice versa. On the other hand, there was evidence of a disjuncture between the simultaneous and serial stimuli in the temporal gradients generated after negative patterning in Experiment 2. The serial groups all showed inhibitory gradients centered on their training intervals, whereas the simultaneous group-Group N0-showed almost complete transfer of inhibition from simultaneous to serial compounds. A reexamination of Figure 4 indicates that, even in the serial groups, there was some evidence for a disjuncture, because all three serial groups showed a sharp rise in responding when the test interval was shortened from 800 to 0 msec.

Our third and fourth questions concerned the generality of temporal specificity across time scales and preparations. The gradients obtained in the present experiments demonstrated that temporal specificity could be obtained over intervals of a few seconds or less. Moreover, the gradients were obtained in a species and response system different from those used in previous demonstrations of temporal specificity. Thus, temporal specificity may be a ubiquitous phenomenon.

At a theoretical level, the present results fully support previous findings that the feature cue in a conditional discrimination performs two duties. It encodes not only probability of the reinforcer but also the timing of the target stimulus and/or the reinforcer (e.g., Barnet \& Miller, 1996; Denniston et al., 1998; Holland et al., 1997). If so, the role of the target stimulus may be only to trigger the response (cf. Konorski \& Lawicka, 1959). Such a conclusion, however, leaves open two important issues. The first concerns the mechanism of temporal encoding; the second concerns the mechanism by which the feature cue interacts with the target stimulus to control the response.

The issue of temporal encoding can be resolved by appeal to the available theories of interval timing. The most general theory assumes that the conditioned properties of an excitatory stimulus include an encoding of the CS-US interval and that an inhibitory stimulus encodes the time of the omitted US (Barnet \& Miller, 1996; Denniston et al., 1998). Other versions vary in their assumptions about the time base for the temporal encoding. Most contend that an organism's nervous system retains a persistent representation of the first event's sensory attributes. This representation has been depicted as a "stimulus trace" (Gormezano \& Kehoe, 1981; Hull, 1943; Kehoe et al., 1987; Pavlov, 1927, p. 39; Sutton \& Barto, 1981, 1990) or a "short-term memory" (Konorski \& Lawicka, 1959; Riley, Cook, \& Lamb, 1981; Roberts \& Grant, 1976). Regardless of its label, this representation is usually assumed to decay in an orderly way so that each successive portion of the representation is distinguishable from other portions (Pavlov, 1927, p. 103).

More recently, information-processing models have proposed that short-term memory does not store a sensory representation but, rather, acts more like a clock. For ex- 
ample, in scalar expectancy theory (Church \& Gibbon, 1982; Gibbon, 1977, 1991), short-term memory acts as a cumulative counter for a string of pulses initiated by the first stimulus. When a reinforcer occurs, the count in this working memory is then stored in reference memory for later retrieval by the stimulus. A theory that is intermediate between the continuous-trace models and pulsebased models can be found in some adaptive timing models of response generation (Desmond, 1990; Desmond \& Moore, 1988).

Regardless of the exact time base, the temporal gradients obtained here and elsewhere can be seen as a species of stimulus generalization. Although the different time bases can explain temporal gradients, integrating these mechanisms with an explanation of the stimulus interactions in patterning and conditional discrimination is more problematic. Moreover, as discussed in the introduction, an explanation of stimulus interaction might no longer be framed in exclusively configural terms or exclusively hierarchical terms. A complete explanation may require a process that can synthesize different types of interaction, as exemplified in connectionist models.

Configural hypotheses can be readily combined with stimulus-like temporal encodings. In a serial stimulus, the portion of A's time code coinciding with the X stimulus would form a configural encoding (e.g., James \& Wagner, 1980; Kehoe et al., 1987; Macrae \& Kehoe, 1995). Thus, responding during the $X$ stimulus in a serial $\mathrm{A} \rightarrow \mathrm{X}$ compound reduces to a discrimination between the configural stimulus arising from the combination of $\mathrm{X}$ with $\mathrm{A}$ 's time code versus the encodings of the separate $A$ and $X$ stimuli. During testing, each $\mathrm{A}-\mathrm{X}$ interval would have superimposed a different portion of A's time code on X, thus generating a different configural encoding and leading to a generalization decrement in the retrieval of the configure's associative strength. Thus, a joint temporal encodingconfigural hypothesis can explain the acquisition and temporal specificity of patterning and conditional discriminations in both simultaneous and serial compounds.

Linking hierarchical hypotheses to a stimulus-like time code is more difficult, because the influence of the A stimulus on responding to the $\mathrm{X}$ stimulus is often thought to be imprecise in its time course. The motivational variants of hierarchical hypotheses have contained explicit assumptions that the conditioned motivational state is recruited slowly and is relatively persistent (Konorski, 1967, p. 281; Wagner \& Brandon, 1989). The "occasion setting" and "facilitation" variants, however, have been less explicit about the time course of the superordinate control mechanism. They seem to allow for temporal specificity. Successive portions of a time code of a feature cue could differentially arouse, say, a "reinforcer expectancy," which in turn would modulate responding to the target stimulus (Holland et al., 1997; Honig \& Thompson, 1982; Peterson \& Trapold, 1980; Terry \& Wagner, 1975).

The incorporation of a time-code mechanism into hierarchical hypotheses might seem to make them indistinguishable from configural hypotheses. However, hier- archical hypotheses would still retain their ability to predict that feature cues and target stimuli can be recombined, a prediction that a configural hypothesis cannot make. Successful recombinations have, in fact, been obtained. For example, a feature cue from one conditional discrimination can transfer its control to a target stimulus from another conditional discrimination (Bonardi, 1996; Holland, 1986, 1989c; Lamarre \& Holland, 1987; Morell \& Holland, 1993; Swartzentruber, 1995; Weidemann \& Kehoe, 1997; Wilson \& Pearce, 1990). Less often, a feature cue has been seen to transfer its control to a CS trained outside a conditional discrimination (Brandon \& Wagner, 1991; see Swartzentruber, 1995, for a review). The addition of a time base suggests that temporal specificity would occur in recombination tests. That is, as seen by Miller and his collaborators, the feature cue would have its strongest effect on a test stimulus when presented at the same time as the original target stimulus (Barnet \& Miller, 1996; Denniston et al., 1998).

A question remains as to how configural and hierarchical mechanisms might operate in tandem across simultaneous and serial stimuli. Connectionist models using layered networks appear to answer this question (Schmajuk \& Buhusi, 1997; Schmajuk et al., 1998; Wagner, 1992). These models have roughly the structure of a unique stimulus version of Rescorla and Wagner's (1972) model (Bellingham et al., 1985; Kehoe \& Graham, 1988; Rescorla, 1972, 1973; Whitlow \& Wagner, 1972). Within the network, each successive portion of A's time code can gain its own associative strength (Desmond, 1990; Desmond \& Moore, 1988; Sutton \& Barto, 1990). These associative strengths would be available for recombination with the associative strengths of target stimuli. At the same time, the portion of A's time code that coincides with $X$ could also form a configural stimulus that acquires its own associative strength. As in the unique-stimulus hypothesis, the strength of these associations would be determined by competition among the simple and configural encodings on the basis of their relative salience and their stimulusreinforcer contingencies.

The possibility that A's time code plays separate roles in the simple encoding of the A stimulus itself and the configural encoding of $\mathrm{AX}$ may help explain the apparent differences between temporal specificity seen in positive patterning versus negative patterning. In positive patterning, there appeared to be a smooth, symmetric transition between simultaneous and serial stimuli, On AX+ trials, the $\mathrm{X}$ and US were closely paired and thus occurred during adjacent portions of A's time code. Consequently, both the simple and configural encodings using A's time code would have acquired strong excitatory strengths and would act in concert with each other. Test manipulations of the A-X interval altered A's time code equally with respect to both its modulation of responding to $X$ and its configural integration with $\mathrm{X}$.

In negative patterning, however, the interplay between the simple and configural encodings of A's time code was potentially asymmetric with respect to simultaneous and 
serial stimuli. In the serial groups, the A-US interval on $\mathrm{A}+$ trials was shorter than the $\mathrm{A}-\mathrm{X}$ interval on $\mathrm{AX}$ - trials. Thus, an early portion of A's time code was paired with the US on $A+$ trials and acquired a high excitatory strength. A later and presumably distinctive portion of A's time code coincided with $X$ on the serial $A X$ - trials and thus acquired an inhibitory potential in its modulatory and/or configural roles. During tests using a simultaneous AX compound, generalization of these inhibitory strengths would be weak and would be unable to counteract summation of the strong excitatory strength of the early portion of A's time code plus the excitatory strength of X. Thus, the high level of responding to the simultaneous $\mathrm{AX}$ test in the serial groups in Experiment 2 can be readily explained.

In Group N0, however, early, adjacent portions of A's time code were paired with the US on A+ trials and coincided with $\mathrm{X}$ on $\mathrm{AX}-$ trials. At the same time, the $\mathrm{X}+$ trials would continue to ensure that $X$ would possess a high excitatory strength. The excitatory effects of the A+ trials would tend to compromise the ability of A's simple encoding to act as a negative modulator on $\mathrm{AX}$ - trials. To counteract the summated excitatory strengths of $A$ and $\mathrm{X}$ on $\mathrm{AX}$ - trials, the configural AX encoding would have to acquire a massive inhibitory strength. The relatively flat gradient of responding in interval testing of Group N0 suggests that this inhibition was so strong that its generalized value in tests with serial $A X$ compounds could counteract the excitatory value of $\mathrm{X}$ plus the generalized excitatory value of A's simple encoding.

If this account is correct, it would predict that a feature negative task should yield an equal degree of temporal specificity in transfer between simultaneous and serial stimuli (Barnet \& Miller, 1996; Denniston et al., 1998). In the feature negative task $(\mathrm{X}+, \mathrm{AX}-)$, the role of A's simple encoding is not compromised by $\mathrm{A}+$ trials and their excitatory effect. Thus, in a simultaneous compound, the simple encoding of $A$ and its AX configural encoding could both acquire an inhibitory strength. The total inhibition would only need to be sufficient to counteract the excitatory strength of X. Finally, this account predicts that temporal specificity would be preserved even if $\mathrm{A}+$ trials were introduced, provided that the A-US interval was different from the A-X interval. Thus, different portions of A's time code could acquire excitatory and inhibitory strengths, respectively.

\section{REFERENCES}

Barnet, R. C., \& Miller, R. R. (1996). Temporal encoding as a determinant of inhibitory control. Learning \& Motivation, 27, 73-91.

Bellingham, W. P., Gillette-Bellingham, K., \& Kehoe, E. J. (1985). Summation and configuration in patterning schedules with the rat and rabbit. Animal Learning \& Behavior, 13, 152-164.

BonARDi, C. (1996). Transfer of occasion setting: The role of generalization decrement. Animal Learning \& Behavior, 24, 277-289.

Brandon, S. E., \& WAGNer, A. R. (1991). Modulation of a discrete Pavlovian conditioned reflex by a putative emotive Pavlovian conditioned stimulus. Journal of Experimental Psychology: Animal Behavior Processes, 17, 299-311.
Church, R. M., \& GibBon, J. (1982). Temporal generalization. Journal of Experimental Psychology: Animal Behavior Processes, 8, 165-186.

Denniston, J. C., Cole, R. P., \& Miller, R. R. (1998). The role of temporal relationships in the transfer of conditioned inhibition. Journal of Experimental Psychology: Animal Behavior Processes, 24, 200-214.

Desmond, J. E. (1990). Temporal adaptive responses in neural models: The stimulus trace. In M. Gabriel \& J. W. Moore (Eds.), Learning and computational neuroscience (pp. 421-456). Cambridge, MA: MIT Press.

Desmond, J. E., \& MOORE, J. W. (1988). Adaptive timing in neural networks: The conditioned response. Biological Cybernetics, 58, 405-415.

GibBon, J. (1977). Scalar expectancy theory and Weber's law in animal timing. Psychological Review, 84, 279-325.

Gibbon, J. (1991). Origins of scalar timing. Learning \& Motivation, 22 , 3-38.

Gormezano, I. (1966). Classical conditioning. In J. B. Sidowski (Ed.), Experimental methods and instrumentation in psychology (pp. 385420). New York: McGraw-Hill.

Gormezano, I., \& GibBs, C. M. (1988). Transduction of the rabbit's nictitating membrane response. Behavior Research Methods, Instruments, \& Computers, 20, 18-21.

Gormezano, I., \& Kenoe, E. J. (1981). Classical conditioning and the law of contiguity. In P. M. Harzem \& M. D. Zeiler (Eds.), Advances in analysis of behavior: Vol. 2. Predictability, correlation, and contiguity (pp. 1-45.). New York: Wiley.

Holland, P. C. (1983). Occasion-setting in Pavlovian feature positive discriminations. In M. L. Commons, R. J. Herrnstein, \& A. R. Wagner (Eds.), Quantitative analyses of behavior: Discrimination processes (pp. 182-206). New York: Ballinger.

Holland, P. C. (1986). Temporal determinants of occasion setting in feature-positive discriminations. Animal Learning \& Behavior, 14, 111-120.

Holland, P. C. (1989a). Feature extinction enhances transfer of occasion setting. Animal Learning \& Behavior, 17, 269-279.

Holland, P. C. (1989b). Occasion setting with simultaneous compounds in rats. Journal of Experimental Psychology: Animal Behavior Processes, 15, 183-193.

Holland, P. C. (1989c). Transfer of negative occasion setting and conditioned inhibition across conditioned and unconditioned stimuli. Journal of Experimental Psychology: Animal Behavior Processes, 15, 311-332.

Holland, P. C. (1992). Occasion setting in Pavlovian conditioning. In D. L. Medin (Ed.), The psychology of learning and motivation (Vol. 28, pp. 69-125). San Diego, CA: Academic Press.

Holland, P. C., \& HaAs, M. L. (1993). The effects of target salience in operant feature positive discriminations. Learning \& Motivation, 24. 119-140.

Holland, P. C., Hamlin, P. A., \& Parsons, J. P. (1997). Temporal specificity in serial feature-positive discrimination learning. Journal of $E x$ perimental Psychology: Animal Behavior Processes, 23, 95-109.

Holland, P. C., \& ReEve, C. E. (1991). Acquisition and transfer of control by an ambiguous cue. Animal Learning \& Behavior, 19, 113-124.

Honig, W. K., \& Thompson, R. K. (1982). Retrospective and prospective processing in animal working memory. In G. H. Bower (Ed.), The psychology of learning and motivation: Advances in research and theory (Vol. 16, pp. 239-283). New York: Academic Press.

Hull, C. L. (1943). Principles of hehavior. New York: AppletonCentury-Crofts.

JAMES, J. H., \& WAGNER, A. R. (1980). One-trial overshadowing: Evidence of distributive processing. Journal of Experimental Psychology: Animal Behavior Processes, 6, 188-205.

KehOe, E. J., \& Gormezano, I. (1980). Configuration and combination laws in conditioning with compound stimuli. Psychological Bulletin, 87, 35l-378.

Kehoe, E. J., \& Graham, P. (1988). Summation and configuration in negative patterning of the rabbit's conditioned nictitating membrane response. Journal of Experimental Psychology: Animal Behavior Processes, 14, 320-333.

Kehoe, E. J., Marshall-Goodell, B., \& Gormezano, I. (1987). Dif- 
ferential conditioning of the rabbit's nictitating membrane response to serial compound stimuli. Journal of Experimental Psychology: Animal Behavior Processes, 13, 17-30.

KONORSKI, J. (1967). Integrative activity of the brain: An interdisciplinary approach. Chicago: University of Chicago Press.

KONORSKI, J., \& LAWICKA, W. (1959). Physiological mechanisms of delayed reactions: 1. The analysis and classification of delayed reactions. Acta Biologiae Experimentalis, 19, 175-197.

LamarRe, J., \& Holland, P. C. (1987). Transfer of inhibition after serial feature negative discrimination training. Learning \& Motivation, 18, 319-342.

Macrae, M., \& Kehoe, E. J. (1995). Transfer between conditional and discrete discriminations in conditioning of the rabbit nictitating membrane response. Learning \& Motivation, 26, 380-402.

Morell, J. R., \& Holland, P. C. (1993). Summation and transfer of negative occasion setting. Animal Learning \& Behavior, 21, 145-153.

Pavlov, I. P. (1927). Conditioned reflexes: An investigation of the physiological activity of the cerebral cortex (G. V. Anrep, Trans.). London: Oxford University Press.

Pearce, J. M. (1987). A model for stimulus generalization in Pavlovian conditioning. Psychological Review, 94, 61-73.

PearCE, J. M. (1994). Similarity and discrimination: A selective review and a connectionist model. Psychological Review, 101, 587-607.

Peterson, G. B., \& TRAPOLD, M. A. (1980). Effects of altering outcome expectancies on pigeon's delayed conditional discrimination performance. Learning \& Motivation, 11, 267-288.

Rescorla, R. A. (1972). "Configural" conditioning in discrete-trial barpressing. Journal of Comparative \& Physiological Psychology, 79, 307-317.

RESCORLA, R. A. (1973). Evidence for "unique stimulus" account of configural conditioning. Journal of Comparative \& Physiological Psychology, 85, 331-338.

RESCORLA, R. A. (1985). Inhibition and facilitation. In R. R. Miller \& N. E. Spear (Eds.), Information processing in animals: Conditioned inhibition (pp. 299-326). Hillsdale, NJ: Erlbaum.

RESCORLA, R. A. (1986). Extinction of facilitation. Journal of Experimental Psychology: Animal Behavior Processes, 12, 16-24

Rescorla, R. A. (1989). Simultaneous and sequential conditioned inhibition in autoshaping. Quarterly Journal of Experimental Psychology, 41B, 275-286.

Rescorla, R. A., \& Wagner, A. R. (1972). A theory of Pavlovian conditioning: Variations in the effectiveness of reinforcement and nonreinforcement. In A. H. Black \& W. F. Prokasy (Eds.), Classical conditioning II (pp. 64-99). New York: Appleton-Century-Crofts.

RILEY, D. A., COOK, R. G., \& LAMB, M. R. (1981). A classification and analysis of short-term retention codes in the pigeon. In G. H. Bower (Ed.), The psychology of learning and motivation: Advances in research and theory (Vol. 15, pp. 51-79). New York: Academic Press.

ROBERTS, W. A., \& GRANT, D. S. (1976). Studies of short-term memory in the pigeon using the delayed matching-to-sample procedure. In D. L. Medin, W. A. Roberts, \& R. T. Davis (Eds.), Processes of animal memory (pp. 79-112). Hillsdale, NJ: Erlbaum.

Ross, R. T., \& Holland, P. C. (1982). Serial positive patterning:
Implications for "occasion setting." Bulletin of the Psychonomic Society, 19, 159-162.

SCANDRETt, J., \& GoRmeZano, I. (1980). Microprocessor control and A/D data acquisition in classical conditioning. Behavior Research Methods \& Instrumentation, 12, 120-125.

SchmajuK, N. A., \& Buhusi, C. V. (1997). Stimulus configuration, occasion setting, and the hippocampus. Behavioral Neuroscience, 111, 235-258.

Schmajuk, N. A., Lamoureux, J. A., \& Holland, P. C. (1998). Occasion setting: A neural network approach. Psychological Review, $105,3-32$.

Sutton, R. S., \& Barto, A. G. (1981). Toward a modern theory of adaptive networks: Expectation and prediction. Psychological Review, 88, 135-171.

Sutton, R. S., \& Barto, A. G. (1990). Time-derivative models of Pavlovian reinforcement. In M. Gabriel \& J. W. Moore (Eds.), Learning and computational neuroscience (pp. 497-537). Cambridge, MA: MIT Press.

Swartzentruber, D. (1995). Modulatory mechanisms in Pavlovian conditioning. Animal Learning \& Behavior, 23, 123-143.

TERRY, W. S., \& WAGNER, A. R. (1975). Short-term memory for "surprising" versus "expected" unconditioned stimuli in Pavlovian conditioning. Journal of Experimental Psychology: Animal Behavior Processes, 1, 122-133.

WAGNER, A. R. (1992). Some complexities anticipated by AESOP and other dual-representation theories. International Journal of Psychology, 27, 101-102.

WAGNeR, A. R., \& BRANDON, S. E. (1989). Evolution of a structured connectionist model of Pavlovian conditioning (AESOP). In S. B. Klein \& R. R. Mowrer (Eds.), Contemporary learning theories: Pavlovian conditioning and the status of traditional learning theory (pp. 149-190). Hillsdale, NJ: Erlbaum.

WEIDEMANN, G., \& KEHOE, E. J. (1997). Transfer and counterconditioning of conditional control in the rabbit nictitating membrane response. Quarterly Journal of Experimental Psychology, 50B, 295-316.

WhITLOW, J. W., JR., \& WAGNER, A. R. (1972). Negative patterning in classical conditioning: Summation of response tendencies to isolable and configural components. Psychonomic Science, 27, 299-301.

Wilson, P. N., \& PEARCE, J. M. (1990). Selective transfer of responding in conditional discriminations. Quarterly Journal of Experimental Psychology, 42B, 41-58.

Woodbury, C. B. (1942). The learning of stimulus patterns in dogs. Journal of Comparative Psychology, 35, 29-40.

\section{NOTE}

1. In describing Rescorla's (1989) experiment, we have changed his letter labels to conform with the pattern of labeling for feature cues and target stimuli used elsewhere in this paper.

(Manuscript received April 17, 1998, revision accepted for publication May 30, 1998.) 